\title{
EL DIALEGTO ESPAÑOL DE RÍO SABINAS VESTIGIOS DEL ESPAÑOL MEXICANO EN LUISIANA Y TEXAS
}

Dentro del territorio norteamericano, existen varios dialectos del español, entre los que sobresalen las variantes de origen mexicano, puertorriqueño, cubano y centroamericano, además de los núcleos pequeños pero importantes de colombianos y dominicanos en Nueva York, de hondureños en Nueva Orleans, de nicaragüenses en Miami, etc. Al margen de estos grupos de impacto mayor, existen otras agrupaciones hispanoparlantes cuyo comportamiento lingüístico se lleva a cabo en ámbitos aislados, y que no afectan en lo más mínimo a las principales variedades del español norteamericano. Podemos señalar las comunidades sefardíes de Nueva York, Seattle y otras ciudades, y el español vestigial de los isleños del estado de Luisiana, descendientes de pobladores canarios que arribaron a Nueva Orleans hacia fines del siglo VIII ${ }^{1}$.

${ }^{1}$ El estudio principal sobre el dialecto isleño es de RAYMOND MACCuRDY, The Spanish Dialect in St. Bernard Parish, Louisiana, University of New Mexico, Albuquerque, 1950; también "Los isleños de la Luisiana: supervivencia de la lengua y folklore canarios", 'AEAtl, 21 (1975), 474-591; "A Spanish wordlist of the "brulis" dwellers of Louisiana", $H, 42$ (1959), 547-554. Véanse también SAMUEl ARMISTEAD, "Romances tradicionales entre los hispanohablantes del estado de Luisiana", NRFH, 27 (1978), 39-56; "Más romances de Luisiana", ibid., 32 (1983), 41-54; Beatriz Varela, "Isleño and Cuban Spanish", Perspectives on Ethnicity in New Orleans, 2 (1979), 42-47; JosEPH Guillotte, Masters of the Marsh: an Introduction to the Ethnography of the Isleños of Lower St. Bernard Parish, Louisiana, University of New Orleans, New Orleans, 1982; JoHn LiPs$\mathrm{KI}$, "The isleño dialect of Louisiana and its importance for historical dialectology", Southwest Journal of Linguistics, de próxima aparición; "Reducción de $/ \mathrm{s} /$ y $/ \mathrm{n} /$ en el español isleño de Luisiana", Revista de Filología de La Laguna, de próxima aparición; "Language contact phenomena in Louisiana isleño Spanish", Hij, de próxima aparición. 
El dialecto español de Tampa, una mezcla de elementos cubanos y peninsulares del siglo XIX, ha sido arrollado por la masiva inmigración cubana de las últimas décadas; ha sucedido lo mismo con el dialecto cubano decimonónico de Cayo Hueso ${ }^{2}$. Queda otro grupo, completamente desconocido fuera del área de residencia, y cuyas características lingüísticas hasta hace muy poco no figuraban en ningún estudio. Estos individuos de habla hispana se encuentran sobre las dos riberas del Río Sabinas (Sabine River), en la parte noroccidental de Luisiana (parroquias de Sabine y Natchitoches) y en la zona nororiental de Texas (condado de Nacogdoches); el español que hablan se diferencia tanto del dialecto isleño de Luisiana como de las variedades contemporáneas del español texano, aunque comparte los antecedentes de esta última categoría ${ }^{3}$. En lo que va a continuación, esbozaremos una descripción de este grupo insólito enclavado en territorio angloparlante, e intentaremos ubicar el dialecto dentro de un marco dialectológico de mayor amplitud.

Los principales lugares de residencia de los individuos ya mencionados son: en Luisiana, cerca de las aldeas de Zwolle y Noble (parroquia de Sabine) y en la comunidad de Spanish Lake, cerca

${ }^{2}$ D. Lincoln Ganfield, "Tampa Spanish: three characters in search of a pronunciation", MLJ, 35 (1951), 42-44; TheOdore BeARdSley, JR., "Influencias angloamericanas en el español de Cayo Hueso", Exilio, 6 (1972), núms. 41/7, 87-100.

${ }^{3}$ La única referencia a estos grupos hecha por un lingüista es de ARMISTEAD, "Más romances...", pp. 41-42; "Un corrido de la muerte de Madero cantado en Luisiana", $A L M, 20$ (1982), 379-387; "Three Spanish dialects in Lousiana", manuscrito inédito, University of California Davis; "Adivinanzas españolas de Loisiana", en Damaso Alonso, Diego García, Rafael LaPESA (eds.), Homenaje a Álvaro Galmés de Fuentes, Gredos, Madrid, 1985, t. 2, pp. 251-262; véase también S. ARMISTEAD y H. GREGORY, "French loan words in the Spanish dialect of Sabine and Natchitoches Parishes"', Louisiana Folklife, 10 (1986), 21-30. Han surgido otros comentarios en torno a la existencia de individuos de habla hispana en el área del Río Sabinas; por ejemplo Donald Sepulvado, "Folk curing in a Spanish community", Louisiana Folklife Neresletter, 2 (1977), núm. 1; José Montero de PEdro, Españoles en Nueva Orleans y Luisiana, Cultura Hispánica, Madrid, 1979, pp. 120-121; Carlos FernánDEZ Shaw, Presencia española en los Estados Unidos, Cultura Hispánica, Madrid, 1972, pp. 344-346; Francis Abernathy, "The Spanish on the Moral”, en The Bicentennial Commemorative History of Nacogdoches, Nacogdoches Jaycees, Nacogdoches, 1976, pp. 21-33; T. Lynn Smith y Homer Hitt, The People of Louisiana, Louisiana State University, Baton Rouge, 1952, p. 47; Hiram GreGORY y James McCorkle, Los Adaes: Historical and Archaeological Survey, Northwestern State University, Natchitoches, 1981. 
del pueblo de Robeline (parroquia de Natchitoches); en Texas, en la comunidad de Moral, unos kilómetros al oeste de Nacogdoches; es posible que queden otras personas de habla hispana más cerca de la frontera estatal, en el condado de San Agustín. Aun más que en el caso de los isleños, ha desaparecido el idioma español en la zona del Río Sabinas; no quedarán más de unos 50 individuos en cada estado que hablan el idioma con soltura, y tal vez la mitad son verdaderos hablantes nativos con plenas capacidades $^{4}$. Aparentemente existen otras personas que poseen unos conocimientos pasivos del español, en que pueden reconocer palabras y frases sueltas, pero que no pueden sostener una conversación en castellano; por lo tanto, ni siquiera llegan al nivel del "hablante a medias" 5 . Los individuos de habla hispana figuran entre los residentes de más edad; los más jóvenes tienen más de 60 años, y los más ancianos sobrepasan los 100 años de edad. Igual que con los isleños, el idioma español desapareció en la zona del Río Sabinas en el transcurso de poco más de una generación, por razones similares.

Los hispanoparlantes del noroccidente de Luisiana se caracterizan por una vida muy sencilla, que consiste en la caza y la crianza de pequeños animales, la tala de madera y en escala menor, el cultivo del algodón. Aun hoy en día, algunos de los habitantes más viejos viven en casas de "palo" que carecen de luz eléctrica y tubería de agua; utilizan la leña para la cocina y la calefacción, y dependen de la crianza de puercos y gallinas y los huertos de cocina para el suministro de víveres. Es tan bajo el nivel de vida que muchos residentes pueden recibir asistencia económica del gobierno federal, y de grupos civiles y religiosos. Algu-

${ }^{4} \mathrm{Mis}$ investigaciones sobre el español del Río Sabinas comenzaron en 1985. Quisiera agradecer de manera especial a las siguientes personas, sin cuya ayuda no habría sido posible la recolección de materiales lingüísticos y bibliográficos: Dr. Hiram Gregory de Northwest State University en Natchitoches, Luisiana; Dr. James Corbin de Stephen F. Austin State University en Nacogdoches, Texas; Dr. Samuel Armistead de la Universidad de California, Davis; Srta. Mary Van Rheenen de Louisiana State University, Baton Rouge; D. Sam Montes de Moral, Texas.

${ }^{5}$ El concepto del "hablante a medias" [semi-speaker] proviene de los trabajos de NANCY DORIAN, "The problem of the semi-speaker in language death", IJSL, 12 (1977), 23-32, y "Language shift in community and individual: the phenomenon of the laggard semi-speaker", ibid., 25 (1980), 85-94. Para un estudio del español vestigial en varias partes del mundo, véase J. LiPSKI, "Creole Spanish and vestigial Spanish: evolutionary parallels", de próxima aparición en Linguistics. 
nos de los residentes no ostentan orígenes hispánicos, pero todas las personas de edad recuerdan épocas anteriores cuando el español se hablaba más que el inglés. En la comunidad de Moral, en Texas, la mayoría de las personas de habla hispana fueron criadas en pequeños "ranchos" como medianeros o pequeños propietarios. También mantenían una vida de gran sencillez, pero el nivel de vida era ligeramente superior al de Luisiana, puesto que eran mayores las posibilidades agrícolas y ganaderas.

En cuanto al aspecto racial, los hispanoparlantes del Río Sabinas presentan un panorama muy variado, pero sobre todo en Luisiana, una proporción significativa es de ascendencia indígena. En años recientes, la comunidad de Ebarb, cerca de Zwolle en Luisiana ha logrado que el gobierno federal le otorgue los derechos de una nación indígena; en la actualidad ningún residente puede hablar los idiomas indígenas regionales, pero hasta hace unas décadas existían grupos de habla amerindia en esa zona de Luisiana. Por razones de conveniencia, los residentes de Ebarb se han identificado con la nación de los Choctaw, pero los datos históricos y lingüísticos sugieren un origen mexicano para los primeros pobladores hispánicos de esta región. Por ejemplo, la expedición del Marqués de Aguayo, que en 1721 fundó la misión española de Los Adaes cerca de la comunidad actual de Spanish Lake, consistía de unos 117 conscriptos, de los cuales sólo 44 eran españoles, siendo los demás de raza mezclada ${ }^{6}$. En la comunidad texana de Moral no es tan evidente el mestizaje, y aunque los propios habitantes califican de "trigueños" a muchos conciudadanos, no se identifican con la cultura indígena norteamericana.

Es curioso notar que las comunidades hispanoparlantes del Río Sabinas carecen de un adjetivo gentilicio que los describa (como el caso de los isleños); algunos investigadores ${ }^{7}$ han propuesto la palabra adaeseños para los habitantes de Spanish Lake y su dialecto pero el término no es de uso general. Al contestar a la interrogativa de cuáles serían las palabras que mejor describen a los

${ }^{6}$ Abernathy, art. cit., p. 25; Alicia TJarks, "Comparative demographic analysis of Texas 1777-1793", Southwestern Historical Quarterly, 77 (1974), núm. 3, 291-338.

7 Por ej. Armistead, "Más romances..." y "Adivinanzas..." El término adaesaños fue empleado por Herbert Bolton, Texas in the Middle Eighteenth Century, University of California, Berkeley, 1915, p. 394, pero no hay evidencia de que esta palabra haya sido empleada por los propios residentes del área en ningún momento, tal como admite ArmisteAD, "Adivinanzas...", p. 251, n. 2. 
residentes de habla hispana, los integrantes de las dos comunidades solían hablar de españoles, pero indicaban que tampoco esta palabra era usual. En inglés, tampoco hay una designación general; algunos emplean la palabra Spanish "español" pero la mayoría prefiere limitarse a la indicación de que una persona speaks Spanish "habla español". A pesar de la incontrovertible evidencia lingüística y etnográfica, los hispanoparlantes de Luisiana rechazan enfáticamente la palabra mexicano y sus equivalentes en inglés, y parecen ignorar la trayectoria que llevó a sus antepasados de México a las provincias orientales de Texas. Por otra parte, los habitantes de Moral utilizan la palabra mexicano sin reparo, tanto para designarse a sí mismos como para caracterizar el dialecto local.

Es escasísima la documentación histórica que permita trazar los orígenes de las comunidades hispanohablantes del Río Sabinas, pero la información disponible indica una inmigración dividida en etapas, que duró más de medio siglo ${ }^{8}$.

España intentó en varias ocasiones la población de la parte oriental de Texas y el área adyacente de Luisiana, pero no fue hasta 1716 que las primeras misiones permanentes fueron fundadas, en Los Aes (San Agustín), Nacogdoches y Los Adaes. Las misiones fueron abandonadas tres años después, debido a los in-

${ }^{8}$ El estudio más detallado es de Herbert Bolton, "The Spanish abandonment and re-occupation of East Texas, 1773-1779", Quarterly of the Texas State Historical Association, 9 (1905), núm. 2, 67-137; también Texas in the Middle Eighteenth Century, pp. 375-446, y The Spanish Borderlands, Yale University, New Haven, 1921, pp. 227-251. Otros estudios de relevancia son: Carlos E. CASTAÑEDA en la serie Our Catholic Heritage in Texas, Von Boeckmann-Jones, Austin, 8 ts.: t. 2, The Winning of Texas 1693-1731, 1936, pp. 144-145; t. 3, The Mission Era: the Missions at Work 1731-1761, 1938, passim.; t. 4, The Mission Era: the Passing of the Missions 1762-1782, 1939, caps. 7 y 8, especialmente pp. 298-302; y t. 6, The Transition Period: the Fight for Freedom 1810-1836, 1950, cap. 8; George Crockett, Two Centuries in East Texas: a History of San Agustine County and Surrounding Territory from 1685 to the Present Time, Southwest Press, Dallas, 1932, pp. 19-58; LouIS NARdINI, My Historic Natchitoches, Louisiana and its Environment, Nardini Publishing, Natchitoches, 1963, pp. 55-88; Viola CARRUTH, Caddo: 1,000, a History of the Shreveport Area from the Time of the Caddo Indians to the 1970's, Shreveport Magazine, Shreveport, 1970, passim. En el tomo conmemorativo The Bicentennial Commemorative History of Nacogdoches, JaMEs MCReYNolds, "An historical survey of Nacogdoches 1690-1779", pp. 2-5; "Survival in East Texas: food, clothing, shelter, 1779-1860", pp. 77-84; y Bill Stewart, "The founding of Nacogdoches by Antonio Gil y Barbo", pp. 34-38. En Archie McDonald, ed., Nacogdoches: Wilderness Outpost to Modern City 1779-1979, Eakin Press, Burnet, TX, 1980, A. MCDonald, "Early Spanish 
cesantes ataques por parte de los indios y los franceses, pero la expedición encabezada por el Marqués de Aguayo las reestableció definitivamente en 1721. Para la segunda mitad del siglo XVIII estas misiones se habían convertido en aldeas prósperas, y las haciendas de los pobladores españoles se extendían desde el extremo oriental de Texas, en Los Adaes, hasta Nacogdoches. El proyecto original del gobierno español había sido la creación de una zona poblada por españoles que protegiese el resto de Texas de los destacamentos franceses en Luisiana, especialmente en Natchitoches; al ser cedido este territorio a España en 1762, desaparecía la urgencia de tal esfuerzo colonizador, y el gobierno español consideró que era más conveniente retirar a todos los pobladores de la problemática región fronteriza. En 1773, los residentes de Los Aes, Nacogdoches y Los Adaes recibieron la orden real de abandonar las poblaciones en un plazo máximo de cinco días, para reubicarse posteriormente en Béxar (San Antonio). Las protestas fueron casi unánimes, puesto que la mayoría de los habitantes eran nativos de la zona, y tuvieron que abandonar sus hogares, sus campos sembrados y las memorias de toda la vida para comenzar el penoso viaje a San Antonio, que duró más de tres meses y provocó la muerte de la cuarta parte de los viajeros. Una vez llegados a San Antonio, los adaesanos fueron víctimas de discriminación por parte de los pobladores de aquella ciudad, recibieron tierras inferiores a las que habían abandonado, y no pudieron apartarse

settlement in Nacogdoches: missions", pp. 11-18; y J. McReYnolds, "Spanish Nacogdoches 1779-1821"', pp. 19-25; 'Mexican Nacogdoches 1812-1836", pp. 26-32; y Family life in a borderland community: Nacogdoches, Texas 1779-1860, tesis doctoral inédita, Texas Tech University, 1978; RuperT RobInson, $T e$ xas: the Lone Star State, Prentice-Hall, New York, 1943, pp. 41-47; JoHN BELISLe, History of Sabine Parish Louisiana, Sabine Banner Press, Many, LA, 1912, pp. 39-68; Elizabetr Johns, Storms Brewed in Other Men's Worlds: the Confrontation of Indians, Spanish and French in the Southwest, 1540-1795, Texas A \& M University, College Station, 1975; Katherine Bridges y W. Deville, "Natchitoches in 1766", Louisiana History, 4 (1936), 145-159; Antonio Acosta RoDRíGUez, La población de Luisiana española 1763-1803, Ministerio de Asuntos Exteriores, Madrid, 1979, pp. 19-33; Odie Faulk, A Successful Failure: the Saga of Texas 1519-1810, Steck-Vaughn, Austin, 1965, p. 127; The Last Years of Spanish Texas 1778-1821, Mouton, La Haya, 1964, pp. 14-15; MATTIE AustiN HATCHER, The Opening of Texas, to Foreign Settlement 1801-1821, University of Texas, Austin, 1917; Documentos para la historia eclesiástica y civil de la provincia de Texas o Nuevas Philipinas 1720-1779, J. Porrúa Turanzas, Madrid, 1961, especialmente la "Carta del señor Barón de Ripperdá al Caballero de Croix", pp. 335-342; William Dunn, Spanish and French Rivalyy in the Gulf Region of the United States, 1678-1702, University of Texas, Austin, 1917. 
de la gran nostalgia que sentían por su tierra natal. Después de varias gestiones realizadas ante el gobierno español en San Antonio, Coahuila y la ciudad de México, los adaesanos recibieron la autorización de reubicarse en un punto intermedio, que llegaron a nombrar Bucanelli, en honor del oficial militar español que los ayudaba. El jefe de la infeliz expedición era Antonio Gil Ybarbo (Ybarburu), un terrateniente oriundo de Los Adaes, quien acabó por fundar el pueblo de Nacogdoches en 1779, sobre el sitio de la antigua misión de Nuestra Señora de Guadalupe. La decisión de no reocupar la misión de Nuestra Señora de los Dolores (Los Aes) radicaba en el hecho de que todos los edificios de ésta habían sido destruidos; es probable que la decisión de no reestablecer la colonia de Los Adaes resultase del deseo de no provocar a las autoridades españolas hacia una nueva orden de desalojamiento. De todas maneras, parece que muchos de los residentes originales de Los Adaes y Los Aes, entre ellos la madre, el hermano la cuñada de Ybarbo, nunca dejaron la región con la evacuación de 1773, sino que permanecían en las zonas silvestres y en la hacienda de Ybarbo, cerca de Los Aes; como resultado, es posible postular una ocupación española continua de la región del Río Sabinas a partir del 1721. Estas colonias se localizan a lo largo del camino real, que se extendía de Natchitoches a San Antonio, hasta llegar a la ciudad de México; por lo tanto, era activo y nutrido el comercio con México y el resto de Texas. Era igualmente abundante el tráfico de contrabando (siendo el propio Ybarbo uno de sus adeptos), el que empleaba una ruta que se desviaba un poco del camino real a fin de evitar el puesto aduanero de $\mathrm{Na}$ cogdoches. Al readquirir Francia el territorio de Luisiana en 1800, los colonos españoles se quedaron, y cuando el gobierno de Estados Unidos le compró todo el territorio a Francia en 1808, la emigración de los angloamericanos empezó a ser un factor de consideración.

Desde la fundación de Nacogdoches en 1779 hasta la independencia mexicana de 1821 , el pueblo apenas creció, y llegó al borde de la extinción total hacia fines del imperio español. Entre 1821 y 1836, al contrario, se produjo un crecimiento dramático, y la población alcanzó los 1.000 habitantes. Esto significa que, a diferencia de las comunidades hispánicas de Zwolle/Ebarb y Spanish Lake en Luisiana, el área de Nacogdoches recibió directamente influencias mexicanas políticas y lingüísticas hasta bien entrado el siglo Xix. No es posible saber a ciencia cierta hasta qué punto los antiguos residentes españoles de Nacogdoches se identificaron 
con el gobierno mexicano, o fueron afectados por él durante el período de 1821 a 1836 . Se sabe, eso sí, que los españoles restantes respaldaban a los emigrantes angloamericanos en varias confrontaciones con el gobierno mexicano, entre ellas la Rebelión de Fredonia (1826) y la Batalla de Nacogdoches (1932). Al mismo tiempo, la emigración angloamericana desde los estados centrales y del sur representaba la mayor parte del incremento poblacional $^{9}$, en un período en que el gobierno mexicano ejercía poco control sobre el extremo oriental de Texas. Por lo tanto, se produjo una creciente marginación social y lingüística de los antiguos residentes españoles aun antes de la revolución texana. Posterior a ésta, aumentó aún más la inmigración de Luisiana a Texas, pero también hubo un movimiento migratorio en sentido contrario ${ }^{10}$, sobre todo de hispanoparlantes disgustados por la invasión de los angloamericanos que se aprovechaban de las mejores oportunidades y tierras. Los residentes españoles de Nacogdoches montaron una fracasada contraofensiva (la rebelión de Córdova) a la revolución texana, y posteriormente resistieron la asimilación a la cultura angloamericana. Puesto que la independencia mexicana se había consumado pocos años antes, es probable que en la región fronteriza del Río Sabinas no se hubiese formado una identidad colectiva de "mexicanos", excepto en cuanto a las confrontaciones con los Estados Unidos. Al anexarse Texas a la unión norteamericana en 1845, la inmigración angloamericana llevaba varias décadas en Nacogdoches, y los residentes de habla inglesa ya constituían la mayoría; los residentes de habla hispana fueron marginados progresivamente, quedando enclavados en la comunidad de Moral. En Luisiana, la inmigración angloamericana había comenzado aun antes, y poco después desapareció el carácter hispánico de Los Adaes.

Los datos que acabamos de exponer trazan los principales contornos históricos de las comunidades hispánicas del Río Sabinas, pero no resuelven la cuestión de las fuentes lingüísticas del dia-

${ }^{9}$ Véanse Robinson, op. cit., pp. 90-92; José María SÁnchez, "A trip to Texas in 1828', tr. C. Castañeda, Southwestern Historical Quarterly, 29 (1926), núm. 4, 249-288, especialmente pp. 282-283.

${ }^{10}$ Barnes Lathrop, Migration into East Texas 1835-1860, Texas State Historical Association, Austin, 1949, cap. 3; E. BARKER, "Notes on the colonization of Texas", Southwestern Historical Quarterly, 27 (1923), 108-119; E. BAGBY ATwood, The Regional Vocabulary of Texas, University of Texas, Austin, 1962, cap. 1; FRED TARPLEY, "Historical aspects of linguistic research in East Texas', East Texas Historical Journal, 2 (1964), núm. 1, 18-25, especialmente p. 19; Sмгтн у Hiтt, op. cit., pp. 212-213. 
lecto español que todavía se habla. En Nacogdoches es corriente la opinión ${ }^{11}$ de que los residentes hispánicos provienen de los primeros isleños, algunos de los cuales habrían llegado al puerto de Nueva Orleáns y seguido el cauce del Río Mississippi y después del Río Colorado (Red River) hasta llegar a Natchitoches, para radicarse definitivamente en Los Adaes. Tal trayectoria querría decir que los hispanoparlantes del Río Sabinas tienen un parentesco peninsular aún menos adulterado que el de los isleños de San Bernardo, pero tal suposición no concuerda con los datos históricos y lingüísticos. Ya se sabe, por ejemplo, de la población de Los Adaes a partir de Coahuila, México y de San Antonio, Texas, aunque es natural que algunos de los pobladores hubieran de casarse con mujeres francesas o indígenas del área de Natchitoches. Después del abandono oficial de Los Adaes por el gobierno español, los colonos que se quedaron atrás sin duda se mezclaban con los vecinos franceses e indígenas. En términos lingüísticos, el dialecto español del Río Sabinas nada tiene que ver con el español isleño de San Bernardo, sino que se deriva claramente del español mexicano rural. Era mínima la emigración española después de la fundación de Nacogdoches, y cualquier compenetración de dialectos se producía a partir de las variantes mexicanas de la época. Si este bosquejo histórico es correcto en sus detalles principales, entonces el español vestigial de Zwolle y Spanish Lake es una continuación directa del vernacular mexicano de fines del siglo XVIII, mientras que el dialecto de Moral puede reflejar unas características mexicanas de las primeras décadas del XIX. Las dos comunidades figurarán entre las más antiguas variedades del español que aún se hablan en Estados Unidos. Los residentes hispánicos del Río Sabinas han retenido el idioma español por razones de aislamiento social y geográfico. En Moral, la invasión angloamericana creó un sentimiento de solidaridad de raza entre los antiguos pobladores españoles, quienes viajaban al "pueblo" de Nacogdoches sólo para conseguir los víveres de primera necesidad, al tiempo que mantenían su religión y su lengua en la zona aislada de Moral. En Luisiana, parece que había menos solidaridad étnica, pero era mayor el aislamiento social puesto que los residentes hispánicos vivían lejos de cualquier población grande, eran pobres, ostentaban un perfil racial diferente del de los vecinos de habla inglesa y francesa, y hablaban un idioma "extranjero". En Luisiana, los niños de habla española no tenían acceso

11 AbERnathy, art. cit., p. 25. 
a la educación pública hasta bien entrado el siglo $\mathrm{xx}^{12}$, y los pocos alumnos que asistían a clases sentían las fuertes presiones para que aprendieran el idioma inglés y lo utilizaran exclusivamente. En efecto, la transmutación lingüística se produjo casi sin excepción, aunque los residentes más viejos retienen un ligero dejo al hablar inglés que los identifica como hispánicos. A medida que iban aumentando las oportunidades económicas, y con la llegada de la electricidad, los teléfonos y las carreteras pavimentadas, se incrementaba el uso del idioma inglés, hasta llegar a la situación actual. Los hablantes actuales del español del Río Sabinas manifiestan cierta ambivalencia hacia el idioma. Aunque es de conocimiento general que en décadas anteriores el español se empleaba como lengua de preferencia en ambas comunidades, el uso del español sigue conllevando cierto estigma social, debido a los antecedentes ya expuestos. El idioma español está asociado a la gente "antigua" y hasta "retrógrada", y la mayoría de los residentes de habla hispana optaron por no enseñar el idioma a sus hijos y nietos. Entre los propios hispanoparlantes, muchos confiesan sentir vergüenza por la calidad de su lenguaje, tildándolo de "quebrado", "pasado de moda", etc. Es posible que estos sentimientos hayan sufrido un incremento al realizarse visitas a las comunidades del Río Sabinas por parte de lingüistas, etnólogos, historiadores y trabajadores sociales, muchos de los cuales hablan variedades cultas del español contemporáneo. En la actualidad, el idioma español se emplea muy poco en las comunidades, y la mayoría de las personas que lo hablan aún hesitan antes de iniciar una conversación en castellano; casi todos pueden hablar con más facilidad al prolongarse la conversación por varias horas o días. Los últimos hispanoparlantes suelen hallar las palabras con dificultad, a veces confunden el significado de las palabras, y aun cuando pretenden hablar "puro español", introducen muchos elementos ingleses, no sólo calcos y préstamos léxicos sino intercalaciones de oraciones enteras que no figuran en el repertorio de los hablantes bilingües más equilibrados.

Al parecer, los pobladores de Los Aes, Nacogdoches y Los Adaes, tanto en la época de la primera fundación de las misiones como durante el retorno de Ybarbo y su expedición, provenían de las capas sociales más bajas del territorio mexicano, siendo en su gran mayoría conscriptos, prófugos y pequeños labradores. Aun los terratenientes como Ybarbo contaban con poca formación in- 
telectual, y a juzgar por la documentación de la época, casi todos los pobladores eran analfabetos y sufrían de una gran ignorancia del mundo más allá de sus pequeñas comunidades. Es natural pensar que el carácter lingüístico del español del Río Sabinas haya de reflejar estos orígenes humildes, y en efecto es posible detectar huellas del origen rústico e inculto del dialecto local.

\section{Características Fonológicas}

Puesto que se deriva esencialmente del español mexicano (sobre todo las variedades norteñas, ya que la mayoría de los pobladores llegaban de Coahuila y la parte central de Texas), el español del Río Sabinas tiene un perfil bastante conservador en la dimensión fonológica ${ }^{13}$. Esto se manifiesta mediante la resistencia general de las articulaciones consonánticas, el lento ritmo, y la falta de extensas neutralizaciones fonológicas que se encuentran en muchos otros dialectos, incluso el de los isleños. Al mismo tiempo, el dialecto del Río Sabinas contiene muchos arcaísmos, formaciones analógicas y transmutaciones fonológicas, debido tanto a sus orígenes rústicos como a su prolongado aislamiento de otras comunidades hispanoparlantes. Entre los pormenores fonéticos figuran los siguientes:

(1) $\mathrm{La} / \mathrm{s} / \mathrm{se}$ realiza como [s] en posición implosiva y final de frase; son relativamente pocos los casos de aspiración [h], aunque en algunas ocasiones, se produce el cambio $/ \mathrm{s} />$ [h] igual que en otros dialectos populares: nosotros $>$ nojotros (o lojotros), etc. En posición final absoluta, la /s/ se pierde a veces, pero esto puede resultar de la naturaleza marginada y vestigial de los últimos restos del dialecto local.

(2) El fonema nasal / $\mathrm{n} /$ tiene articulación uniformemente alveolar [n] en posición final absoluta y final de palabra ante vocal.

(3) La variante fricativa de /h/ se realiza como labiodental [v] en una alta proporción de los casos.

13 Pueden consultarse las siguientes: JosePH MATLuCK, La pronunciación del español en el Valle de México, UNAM, México, 1951; Peter Boyd-Bowman, El habla de Guanajuato, UNAM, México, 1960; DANiel CÁrdenAs, El español de Jalisco, C.S.I.C., Madrid, 1967; Charles Marden, The Phonology of the Spanish Dialect of Mexico City, Johns Hopkins University, Baltimore, 1986; GioRGio PE. RIsSinotTo, Fonología del español hablado en la ciudadide México, El Colegio de México, México, 1975; D. Lincoln Canfield, Spanish Pronunciation in the Americas, University of Chicago, Chicago, 1981, pp. 60-64. 
(4) Se neutraliza parcialmente la oposición entre los fonemas vibrantes $/ \mathrm{r} / \mathrm{y} / \overline{\mathrm{r}} /$ en favor de la variante simple $[\mathrm{r}]$. Esta neutralización también tiene lugar en otros dialectos vestigiales y acriollados del español ${ }^{14}$, pero no es característica de los principales dialectos del español mexicano. La neutralización de las vibrantes en el dialecto del Río Sabinas puide ser otra consecuencia de la erosión idiomática de las últimas generaciones hispanoparlantes, pero la extensión de la reducción $/ \overline{\mathrm{r}} />[\mathrm{r}]$ hace sospechar un origen algo más temprano. En posición implosiva, $/ \mathrm{r} / \mathrm{se}$ realiza como [r], pero al final de la frase no es insólita su elisión, sobre todo en los verbos infinitivos, otro proceso que no caracteriza al español mexicano.

(5) El fonema /y/ tiene realización débil, y se elide con facilidad en contacto con $/$ i/ (gallina $>$ [gaína], silla $>$ [sía]) y después $\mathrm{de} / \mathrm{el} /$ (sello $>$ [sen]), igual que en las variedades norteñas del español mexicano y en los dialectos centroamericanos ${ }^{15}$. Esto muy probablemente refleja la pronunciación de los primeros pobladores españoles en el extremo oriente texano.

(6) El fonema fricativo posterior $/ x /$ se realiza con poca fricción velar, siendo apenas una ligera aspiración [h]; ésta es más parecida a la pronunciación centroamericana y al español mexicano del norte, pero también puede provenir del origen andaluz/canario de algunos de los primeros pobladores.

(7) Se produce una neutralización parcial entre $/ \mathrm{d} / \mathrm{y} / \mathrm{r} / \mathrm{en}$ posición intervocálica, casi siempre en favor de $[\mathrm{r}]$ (por ej. cada $>$ [kara]), aunque la variabilidad idiolectal es considerable. Esta neutralización no es característica de ningún dialecto mexicano, y su presencia sólo entre la última generación de hispanoparlantes vestigiales (y también entre los últimos isleños y otros grupos marginados en Estados Unidos) puede deberse a la influencia del inglés.

(8) El fonema / $/$ / a veces adquiere una realización alveolar, y puede articularse como vibrante sorda [r]; esto parece deberse directamente a la influencia del inglés.

(9) Los hispanohablantes del Río Sabinas suelen reducir las vocales átonas dándoles una articulación centralizada [e] o [ə]. En el español mexicano es frecuente el ensordecimiento y la elisión de vocales átonas ${ }^{16}$, pero en el dialecto del Río Sabinas es

\footnotetext{
${ }^{14}$ LIPSKI, "Creole Spanish and vestigial Spanish"; Germán DE Granda, "La desfonologización de $/ \mathrm{r} /-/ \mathrm{r} /$ en el dominio lingüístico hispano", BICC, 24(1969), 1-1l.

${ }^{15}$ Canfield, op. cit., p. 15; J. Ronald Ross, "La supresión de /y/ en el español chicano', $H, 63$ (1980), 552-554.

${ }^{16}$ JUAN LOPE BlANCH, "En torno a las vocales caedizas del español mexi-
} 
más corriente la centralización; esto puede resultar del prolongado aislamiento del dialecto, así como de la influencia del inglés.

(10) Igual que en el dialecto isleño y otras manifestaciones vestigiales, el español del Río Sabinas se caracteriza por la transmutación fonológica, tanto en casos espontáneos como en un proceso gradual de relexificación. Entre los ejemplos más frecuentes podemos citar: bujero < agujero; jolote/jalote < guajolote; murcégalo < murciélago; los/losotros/lajotros < nos/nosotros; etc.

\section{CARACTERÍSTICAS MORFOSINTÁCTICAS ${ }^{17}$}

Como ya hemos señalado, el dialecto español del Río Sabinas contiene muchos arcaísmos y rusticismos, y en las últimas generaciones de hablantes vestigiales, existe evidencia de la transferencia sintáctica a partir del inglés. Entre los principales rasgos morfosintáticos del dialecto están:

(1) Arcaísmos, tales como trujo/truje, vido/vide, mesmo, muncho, asinalansina.

(2) Formas analógicas de algunos paradigmas verbales, generalmente con el efecto de reducir el polimorfismo y crear una raíz invariable; cierramos $<$ cerramos, dijieron $<$ dijeron, cocinear $<$ cocinar, tinimos < tuvimos, etc.

(3) El empleo de mero con el valor de 'mismo', igual que en el español mexicano popular: aqui mero, éste mero, ya mero 'casi', etc.

(4) La combinación de nosotros goza de exclusividad, siendo prácticamente desconocidas las formas nuestro, nuestra, etc.

cano", NRFH, 17 (1966), 1-19; JoSEPH MATLUCK, "La $e$ trabada en la ciudad de México", $A L M, 3$ (1963), 5-34; Peter Boyd-Bowman, "La pérdida de vocales átonas en la planicie mexicana", $N R F H, 6(1952), 138-40$; MARía Canellada y Alonso Zamora Vicente, "Vocales caducas en el español mexicano", ibid., 14 (1960), 221-224.

17 Véanse las siguientes obras, además de las citadas en la nota 14: AURELIo Espinosa, Estudios sobre el español de Nuevo México, tr. A. Alonso y A. Rosenblat, Universidad, Buenos Aires, 1930. (BDH, 1); The Spanish Language: New Mexico and Southern Colorado, Historical Society of New Mexico, Santa Fe, 1911; JaCOB ORNSTEIn, "The archaic and the modern in the Spanish of New Mexico", H, 34 (1951), 137-142; Aurelio Espinosa, JR., "Problemas lexiográficos del español del sudoeste", ibid., 40 (1957), 139-143; AnITA Post, "Some aspects of Arizona Spanish", ibid., 16 (1933), 35-42; JuAn RAEL, "Associative interference in New Mexican Spanish", $H R, 7$ (1939), 324-336; FrITZ HENSEY, "Grammatical variation in southwest American Spanish", Ling, 108 (1973), 5-26. 
(5) Las combinaciones con base en no más 'sólo, mismo', igual que en el español mexicano popular: no más queria platicar contigo, aqui no más, etc.; por otra parte, no se intercala no más como en el español andino (por ej. ¿qué no más quieres?).

(6) Los hispanoparlantes del Río Sabinas emplean el verbo estar en varios casos en los que el español mundialmente, aun los dialectos populares de México, prefiere ser: Esto puede resultar del carácter vestigial del actual dialecto, pero casi todos los hablantes de las dos comunidades del Río Sabinas emplean las mismas combinaciones, lo cual hace pensar que se producía una desviación sintáctica gradual a partir del habla mexicana popular de fines del siglo XVIII. Entre los ejemplos de nuestro corpus figuran:

toa la gente que 'ta aquí 'ta blanco

los Peñas están trigueños

una coquena 'ta medio amarillo

el tacuache no 'ta malo

el caldo blanco tenía hojas que 'taban medio blancos

si 'taban novios por mucho tiempo

(7) Igual como el español mexicano, el habla del Río Sabinas prefiere las formas interrogativas ¿qué tanto?/¿qué tan? en vez de ¿cuánto?, siendo casi desconocida esta última forma: ¿qué tanto ganas?, ¿qué tan vieja es esta casa?

(8) Los hispanoparlantes del Río Sabinas emplean la construcción para atrás (patrás) como aparente calco sintáctico de la partícula verbal back del inglés: venga patrás 'vuelva, regrese', vamos patrás 'volvamos', te pago patrás 'te devolveré el dinero', etc. Este mismo calco se produce en otras regiones de bilingüismo anglohispánico, entre las personas de origen mexicano, puertorriqueño y cubano en los Estados Unidos, entre los isleños de Luisiana, en Puerto Rico, en la isla caribeña de Trinidad, y en la colonia británica de Gibraltar ${ }^{18}$. Entre las varias comunidades bilingües dentro de Estados Unidos habría que postular un origen común para las combinaciones a base de patrás, aunọne en muchos casos los contac-

${ }^{18} \mathrm{JOHN}$ LIPSKI, "Constructions with pa(ra) atrás among Spanish-English bilinguals; common structures and universal tendencies", de próxima aparición en Revista/Review Interamericana; RoSAURA SÁNCHEZ, "Nuestra circunstancia lingüística”, El Grito, 6 (1972), 45-74; PAulino Pérez SAla, Interferencia lingüísti- 
tos entre los grupos han sido escasísimos. Sin embargo, la existencia de la misma combinación fuera del ámbito norteamericano fortalece la hipótesis de una generación paralela en distintos lugares, y la presencia de patrás en el dialecto español del Río Sabinas podría representar otro ejemplo de evolución paralela. En Nacogdoches, se han producido algunos contactos entre los residentes hispanoparlantes de Moral y los mexicoamericanos que han emigrado desde otras regiones de Texas, pero no ha habido otros préstamos verificables del español mexicano o "chicano" contemporáneo en el dialecto del Río Sabinas; en el caso de las comunidades de Luisiana, no ha habido contactos generalizados entre los residentes hispanoparlantes y personas de habla mexicana/mexicoamericana. Es probable que la formación de combinaciones a base de patrás en las comunidades ya mencionadas haya sido respaldada por el empleo frecuente de para con sentido direccional en el español mexicano popular: me voy pa' l pueblo. En nuestro corpus encontramos ejemplos como:

venga patrás mañana

habla patrás [responde] en español

unos vinieron patrás con él

\section{Características LÉXICAS ${ }^{10}$}

El léxico del dialecto del Río Sabinas contiene una variedad de mexicanismos, arcaísmos y rusticismos generalizados, unos aparentes indigenismos de origen local, y en Luisiana, unos préstamos del francés acadiano. En la actualidad, se están llevando a cabo varias encuestas lexicográficas en esta zona, cuyos resulta-

ca del inglés en el español hablado en Puerto Rico, Inter American University, Hato Rey, 1971; Mary Ellen García, "Pa(ra) usage in United States Spanish", $H, 62$ (1979), 106-114; "Syntactic variation in verb phrases of motion in United States-Mexican Spanish", en J. Amastae, L. Elías-Olivares, eds., Spanish in the United States: Sociolinguistic'Aspects, Cambridge University, Cambridge, 1982, p. 82-92; Beatriz Varela. "La influencia del inglés en los cubanos de Miami y Nueva Orleans", $E A C, 1974$, núm. 26, 16-25.

19 Véanse Francisco Santamaría, Diccionario de mejicanismos, Pedro Robredo, México, 1959; Diccionario general de americanismos, Pedro Robredo, México, 1942; LeOvigildo Islas Escacega, Vocabulario campesino nacional, Secretaría de 
dos pueden esclarecer muchos puntos inciertos sobre el dialecto del Río Sabinas. En el presente estudio, nos limitaremos a señalar las principales características léxicas, a fin de demostrar los orígenes mexicanos del habla hispánica del Río Sabinas.

(1) Mexicanismos. De los regionalismos identificables, son los más numerosos. Podemos citar atole, guajolote, tecolote, zopilote, cacahuate, zacate, camote, tamal, tortilla (estas dos comidas preparadas al estilo mexicano), comal, nixtamal, metate, molcajete, petate, mecate, cuate, tapanco, coquena, tacuache, tejón, güero, elote, ejote, charola, labor 'división de tierra', blanquillo, tuza, ándale, pinche, y las maldiciones a base de chingar.

(2) Arcaísmos/rusticismos. Entre los más corrientes podemos citar: mercar/marcar 'comprar', calzón/calzones 'pantalón', túnico 'vestido de mujer', calesa, la provisión 'los víveres necesarios para sostener la familia', noria 'pozo de agua o de petróleo', truja/traja 'granero', palo 'árbol, tronco de árbol', peje, fierro, lumbre 'fuego', borrego, prieto.

(3) Otros elementos. Entre las palabras de posible origen latinoamericano, acadiano, inglés y amerindio, son pocas las que se emplean entre todos los hispanoparlantes del Río Sabinas: huaguin (waguin) 'carretera', payaso 'murciélago', que alterna con murcégalo; maní, que alterna con cacahuate y, en Luisiana, con el anglicismo regional goober; ojo negro 'especie de frijol conocido en inglés como black-ayed pea', pan de molino 'pan hecho con harina de maíz', y las palabras cusca/cushca, que alternan con el mexicanismo zopilote para designar el buitre. Es desconocida la etimología de cusca, pero puede tener algo que ver con cusca/chusca usado en México y otras regiones hispanoamericanas con el sentido de 'prostituta disimulada'. En vista de la referencia metafórica payaso para el murciélago en el dialecto hispánico del Río Sabinas, es posible que cusca/cushca también sea el producto de una extensión metafórica e irónica para designar al ave de rapiña que señala la presencia de la muerte ${ }^{20}$. Otras etimologías posibles son 'perso-

Agricultura y Fomento, México, 1945; JoRge Prieto MejÍA, Así habla el mexicano, Panorama, México, 1981; Roberto Galván y Richard Teschner, El diccionario del español chicano, Institute of Modern Languages, Silver Spring, MD, 1977; Léxico del habla culta de México, Centro de Lingüística Hispánica, UNAM, 1978; Gilber to Cerda, Berta Cabaza y Julieta Farías, Vocabulario español de Texas, University of Texas, Austin, 1953.

${ }^{20}$ Santamaría, Diccionario general de americanismos, t. 1, pp. 445, 552; Me JíA PRIETO, op. cit., p. 38, quien postula una etimología a partir de cuscuta, una planta chupadora. Véase también CIRO BAYO, Manual del lenguaje criollo de Cen- 
na entrometida'21, 'jorobado'22, 'perro faldero o que ladra mucho'23, 'glotón'24, o 'carne en descomposición'25.

Igualmente significativa es la ausencia, en el dialecto del Río Sabinas, de otros mexicanismos de uso contemporáneo, tales como chamaco, huerco, chavalo (sólo se emplea chicuelo), y el uso de gabacho para referirse a los norteamericanos. La ausencia de esta última palabra, que anteriormente era usada por los españoles para designar a los franceses, puede deberse al período de formación de los dialectos del Río Sabinas, que antecede a la invasión angloamericana de Luisiana y Texas y las consecuentes tensiones nacionales y raciales. Es probable que el uso de gabacho con sentido de "'norteamericano" se haya producido en México después de la guerra de 1848; de todas maneras, es curioso notar la prevalencia de bolillo con el mismo sentido, entre los hispanoparlantes del Río Sabinas, donde a veces se emplea para referirse a cualquier forastero que no sea de la comunidad local. También podemos citar la ausencia del epíteto gachupin en el dialecto del Río Sabinas, aplicado a los descendientes de "españoles".

\section{Conalusiones}

No es posible una reconstrucción total de los dialectos originales que habrían de dar lugar al español del Río Sabinas, debido a la falta de documentación histórica adecuada y al número muy reducido de hablantes contemporáneos. Sin embargo, ha sido factible trazar los contornos generales de dicho dialecto, y sus conexiones con los dialectos mexicanos de antaño. Es evidente, por ejemplo, que para comienzos del siglo XVIII, el español que se hablaba en Texas tenía más características mexicanas que pe-

tro y Sudamérica, Rafael Scaro Raggio, Madrid, 1931, p. 107, donde figura la palabra chusco con el sentido de 'gallo ordinario'.

${ }^{21}$ José Vicente Solá, Diccionario de regionalismos de Salta, Talleres Gráficos de Sebastián de Amorrorta e Hijos, Buenos Aires, 1956, p. 102.

22 Americanismos, diccionario ilustrado Sopena, Ramón Sopena, Barcelona, 1982, p. 209.

${ }^{23}$ Charles Kany, American Spanish Euphemisms, University of California, Berkeley, 1960, p. 188; Isaías Lerner, Arcaísmos léxicos del español de América, Ínsula, Madrid, 1974, p. 118.

${ }^{24}$ Rubén Cobos, A Dictionary of New Mexico and Southern Colorado Spanish, Museum of New Mexico Press, Santa Fe, 1983, p. 41; Santamaría, op. cit., t. 2, p. 86 .

${ }^{25}$ Solá, op. cit., p. 131. 
ninsulares, y que los mexicanos habían penetrado el lenguaje de personas sin ascedencia indígena o mestiza. También podemos postular el ínfimo nivel sociocultural de los primeros pobladores de la frontera texana, tal como se ve reflejado en el alto índice de rusticismos en el dialecto actual del Río Sabinas. Es imprescindible la realización de más estudios sobre este interesante dialecto, que se halla al borde de la extinción total, a fin de remediar algunas de las lagunas informáticas sobre el desarrollo y la difusión del español americano.

JOHN M. LIPSKI

University of Houston 